\title{
Verticillium dahliae Resistance in Horseradish Germ Plasm from the University of Illinois Collection
}

\author{
N. Atibalentja and D. M. Eastburn, Department of Crop Sciences, University of Illinois, Urbana 61801
}

\begin{abstract}
Atibalentja, N., and Eastburn, D. M. 1998. Verticillium dahliae resistance in horseradish germ plasm from the University of Illinois collection. Plant Dis. 82:176-180.

A total of 113 horseradish cultivars from the University of Illinois germ plasm collection at Urbana were evaluated for their reaction to Verticillium dahliae in the greenhouse following a root-dip inoculation. Root discoloration was rated 2 months after inoculation on a scale of 0 to 3 as follows: $0=$ no symptoms; $1=$ trace to less than $10 \%$ of the root cross-section with vascular discoloration; $2=10$ to $50 \%$ of the root cross-section with vascular discoloration; and $3=$ more than $50 \%$ of the root cross-section with vascular discoloration. The cultivars exhibited a large amount of variation in response to $V$. dahliae infection, with mean root discoloration ratings ranging from 0.2 to 2.6. The frequency distribution of responses of the 113 cultivars was normal, with a mean and a standard deviation of 1.2 and 0.4 , respectively. Six cultivars, $635 \mathrm{~A}$, 1236A, 769A, 125A, 761A, and 28A, were identified as resistant to $V$. dahliae. The existence of resistance to $V$. dahliae in horseradish germ plasm from the University of Illinois collection is a great resource for the breeding of improved horseradish cultivars that will combine resistance to $V$. dahliae with other desirable characters.
\end{abstract}

Horseradish, Armoracia rusticana P. Gaertn., B. Mey. \& Scherb, is grown for its white, fleshy, and pungent roots, used in the preparation of condiments for meats and seafood (4,9). Approximately half of the annual horseradish supply of the United States (6 million $\mathrm{kg}$ in over $800 \mathrm{ha}$ ) is produced in the Mississippi River Valley, near East St. Louis, Illinois (14). Two other major production areas include Eau Claire, Wisconsin and Tulelake, California, with the remainder of the production coming from Washington State, Michigan, Ohio, Pennsylvania, New Jersey, Connecticut, and Massachusetts $(14,19,21)$.

Yield losses due to Verticillium wilt of horseradish result from the discoloration and deterioration of the root following colonization by Verticillium dahliae Kleb $(5,7,12,13)$. Infection by $V$. dahliae is usually followed by invasion by secondary pathogens, including bacteria such as Pseudomonas spp. and fungi such as Fusarium spp. $(5,12,13)$. Root infection by

Corresponding author: D. M. Eastburn

E-mail: eastburn@uiuc.edu

Portion of a thesis submitted by the first author in partial fulfillment of the requirements for the degree of Master of Science in Plant Pathology.

The first author was supported by a fellowship from the Cameroon Institute of Agronomic Research and the World Bank.

Accepted for publication 15 October 1997.

Publication no. D-1997-1201-01R

(C) 1998 The American Phytopathological Society
$V$. dahliae may or may not result in the expression of foliar symptoms. When such symptoms develop, they start from the lower leaves and progress upward. Affected leaves exhibit chlorosis followed by necrosis. Symptoms often start near the leaf margins and progress inward along the veins, resulting in a characteristic V-shaped lesion. Symptoms commonly develop on one-half of a leaf. A cross-section of the petiole reveals some blackening of the vascular tissue from which the pathogen can be isolated (2).

The damage caused by Verticillium wilt of horseradish is such that many of what formerly were the most productive fields have become unusable for the production of this crop (5). The economic importance of losses incurred by the horseradish industry, and the failure to achieve satisfactory control of the disease through the use of chemicals or crop rotation $(3,12, \mathrm{D}$. M. Eastburn, unpublished data) have prompted the search for alternative strategies against Verticillium wilt of horseradish (1). Host plant resistance has the potential to reduce crop losses with a minimum effort by growers in an environmentally safe, cost-effective manner. In addition, resistance can be combined with other control measures to achieve optimal levels of disease management. Germ plasm collections have proved to be rich sources of resistance for various pests and pathogens $(8,20,22)$. The University of Illinois horseradish germ plasm collection at Urbana originally consisted of 200 cultivars either imported from various places around the world or developed in the United States (14-16,21). The objective of this study was to evaluate the available cultivars for resistance to $V$. dahliae.

\section{MATERIALS AND METHODS}

Root cuttings (sets) were harvested from each of the 154 surviving cultivars, out of 200 cultivars originally listed, in the University of Illinois horseradish germ plasm collection at Urbana. The materials were stored in a cold room $\left(4^{\circ} \mathrm{C}\right)$ until used, at which time sets with no vascular discoloration symptoms were selected and sectioned into 2-cm-diameter fragments $8 \mathrm{~cm}$ long. The sets were washed under tap water, surface-sterilized in $70 \%$ ethanol for 15 $\mathrm{s}$ and $0.5 \%$ sodium hypochlorite $(\mathrm{NaOCl})$ for $10 \mathrm{~min}$, rinsed in tap water, and blotted dry. Surface-sterilized sets were planted immediately in flats ( 35 by 50 by $10 \mathrm{~cm}$ ) filled with a steam-sterilized potting mix (1:1:1, soil:peat:perlite). The flats were kept in the greenhouse for 3 to 4 weeks, until the sets sprouted.

Inoculum preparation and inoculation procedure. The 3- to 4-week-old seedlings were gently removed from the potting mix, washed under running tap water, and inoculated by means of a modified root-dip technique (2), with a 1:1 (vol/vol) mixture of 2 horseradish isolates of $V$. dahliae, HR001 and HR015 (5), at a combined concentration of 100 microsclerotia/ml water, based on counts with a hemacytometer. The roots were dipped in the inoculum suspension for approximately $60 \mathrm{~s}$. Fresh inoculum was used for every 18 plants. Inoculated seedlings were transplanted immediately into potting mix in flats ( 35 by 50 by $10 \mathrm{~cm}$ ) with 9 seedlings/flat.

Experimental design. The sequence in which seedlings were inoculated and transplanted in the flats was based on a completely randomized design, whereby cultivars were the treatments and seedlings within cultivars were the replications. Before inoculation, seedlings were assigned code numbers indicating their cultivar and replicate number. The code numbers were then randomized with a computer software random number generator. At the end of the inoculation process, the flats containing the inoculated plants were randomized on greenhouse benches.

Disease evaluation. After inoculation, plants were grown in the greenhouse for 2 months at 25 to $30^{\circ} \mathrm{C}$, under natural light supplemented with a combination of 1,000watt high-pressure sodium- and mercuryvapor lamps set to a 12-h/day photoperiod. 
Plants were watered as needed. A slowrelease fertilizer, Osmocote 14-14-14 (Grace-Sierra Horticultural Product Co., Milpitas, CA), was applied as a top dressing (90 g/flat) 2 weeks after inoculation. Plants were sprayed twice with Orthene, $75 \%$ acephate (Valent U.S.A. Corporation, Walnut Creek, CA), at the rate of $75 \mathrm{~g} / \mathrm{liter}$, to control green peach aphids (Myzus persicae Sulz).

Plants were observed regularly for foliar symptoms of Verticillium wilt, and attempts were made to differentiate symptoms believed to be caused by $V$. dahliae from those with other causes. For a given cultivar, the incubation period was recorded as the time (days) from inoculation to the first appearance of foliar symptoms typical of Verticillium wilt. Before harvest, plants were rated separately for foliar symptoms typical of Verticillium wilt and general foliar symptoms. Ratings of general foliar symptoms were based upon slight modifications of the 0 to 5 scale of Chang and Eastburn (3), as follows: $0=$ no symptoms; 1 = incipient chlorosis limited to one leaf; $2=2$ to less than $25 \%$ of the leaves with chlorosis and necrosis; $3=$ $25 \%$ to less than $50 \%$ of the leaves with chlorosis and necrosis; $4=50 \%$ to less than $75 \%$ of the leaves with chlorosis and necrosis, with or without stunting of the plant; and $5=$ more than $75 \%$ of the leaves with chlorosis, necrosis, with or without severe stunting, or the plant is dead. These ratings included foliar symptoms typical and atypical of Verticillium wilt. A 0 to 5 scale also was used to rate foliar symptoms typical of Verticillium wilt, as follows: $0=$ no symptoms or any ambiguous symptoms, including the stunting of the plant, that could not be confidently related to $V$. dahliae; 1 to 5 were defined as above, but applied only to chlorosis and necrosis believed to result from Verticillium infection. The death of a plant was attributed to $V$. dahliae only if it resulted from symptoms previously identified as typical of Verticillium wilt.

Root harvest, rating of root discoloration symptoms, and recovery of $V$. dahliae were conducted as previously reported (2). Specifically, the severity of root discoloration symptoms was rated on a 0 to 3 scale, as follows: $0=$ no symptoms; $1=$ trace to less than $10 \%$ of the root cross-section with vascular discoloration; $2=10$ to $50 \%$ of the root cross-section with vascular discoloration; and $3=$ more than $50 \%$ of the root cross-section with vascular discoloration. The experiment was repeated for all cultivars identified as resistant during the first trial, and for some representatives of the other classes of root reaction.

Statistical analysis. An analysis of variance (ANOVA) was performed on the root symptom ratings from the first trial with the general linear models procedure of SAS software (SAS Inc., Cary, NC). Two Pearson correlation coefficients, $r$ (simple) and $r_{p}$ (phenotypic), were computed on a per-plant and per-cultivar basis, respectively, for each combination of the characters observed, using the correlation procedure of SAS (SAS Inc.). A pooled correlation coefficient was calculated for combinations where $r$ or $r_{p}$ were homogeneous (18) over the two trials. Cultivar means for root symptom ratings during the first trial were partitioned into four classes (11) of root reaction, with a clustering procedure of SAS (PROC FASTCLUS, SAS Inc.). Thereafter, cultivar means for the characters that correlated with the root discoloration symptom were sorted relative to the four classes of root reaction, and the data subjected to ANOVA to test the hypothesis of no differences among the class means for those characters. A quadratic canonical discriminant function (10) was derived from the results of cluster analysis (PROC DISCRIM, SAS Inc.). This function served as the classification criterion for the cultivars tested in the second trial.

\section{RESULTS}

During the first trial, 10 of the 154 cultivars grown in the greenhouse to produce seedlings were eliminated from the study because sets rotted prior to emergence. An additional 31 cultivars were discarded because sets had not developed enough secondary roots by the time of inoculation. Therefore, only 113 cultivars with at least three sets that could be assayed for the severity of root discoloration symptoms were considered in this study. Cultivar means for root symptom ratings ranged from 0.2 to 2.6 , and their frequency distribution was not significantly different $(P=$ 0.20 ) from a normal distribution with a mean and a standard deviation of 1.2 and 0.4 , respectively (Fig. 1). Reactions of all cultivars evaluated are available upon request (1). The analysis of variance revealed significant $(P<0.01)$ differences among cultivar means for root symptom ratings. Cluster analysis was used to partition the range of cultivar means for root symptom ratings into four classes of root reaction, because of excessive overlapping of the results obtained with Fisher's least significant difference (FLSD) and Waller-Duncan Bayesian least significant difference (BLSD) tests for mean separation. The four classes, referred to as R, MR, MS, and $\mathrm{S}$, for resistant, moderately resistant, moderately susceptible, and susceptible, respectively, were delimited as follows: $0 \leq$ $\mathrm{R} \leq 0.7 ; 0.7<\mathrm{MR} \leq 1.2 ; 1.2<\mathrm{MS}<2.0$; and $2.0 \leq \mathrm{S}$; with corresponding frequencies of $17,43,48$, and 5 cultivars.

The four classes of root reaction differed significantly $(P<0.05)$ for the incubation periods, the severity and incidence of typical foliar symptoms of Verticillium wilt, and the recovery of the pathogen. On average, incubation periods were shorter, whereas the severity and incidence of typical foliar symptoms were higher in the susceptible than in the resistant cultivars (Table 1). Likewise, recovery of the pathogen was more frequent for susceptible than for resistant cultivars.

A quadratic canonical discriminant function, $Y=-7.53+6.21 x$, where $x$ represents a cultivar mean for the severity of root discoloration symptoms, was derived from the partition of cultivars obtained through cluster analysis. This function was used to classify the 22 cultivars evaluated in the second trial. Of the 17 cultivars previously described as resistant, 6 were confirmed as resistant, 9 were classified as moderately resistant, and 2 were transferred to the moderately susceptible class of cultivars (Table 2). One cultivar, 109A, initially identified as moderately resistant, was classified as resistant in the second trial. The remaining cultivars were reassigned to their original classes, although 647 A and 1405A, included in the second trial as standard susceptibles, were classified as moderately susceptible.

During the two trials, $V$. dahliae was not recovered from asymptomatic sets; however, the pathogen was recovered with increasingly higher frequencies, 25, 74, and $82 \%$ from sets with root symptom

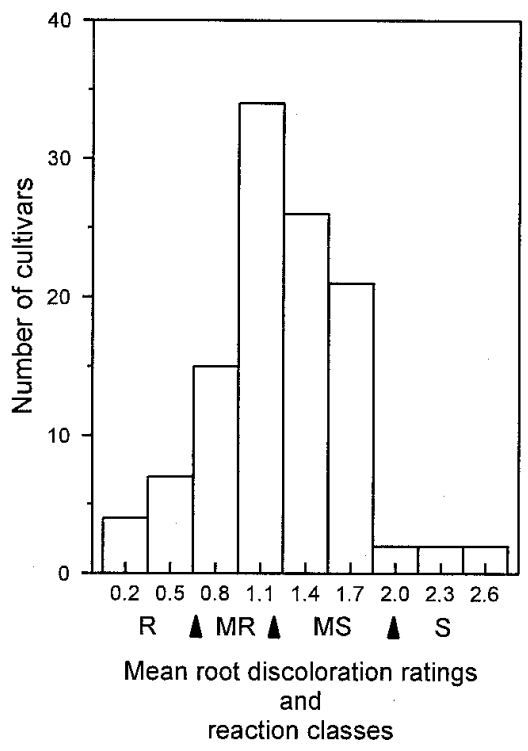

Fig. 1. Frequency distribution of 113 horseradish cultivars from the University of Illinois germ plasm collection for the severity of root discoloration symptoms 2 months after root-dip inoculation with Verticillium dahliae (100 microsclerotia/ml water). Root discoloration was rated on a 0 to 3 scale as follows: $0=$ no symptoms; $1=$ trace to less than $10 \%$ of the root cross-section with vascular discoloration; 2 $=10$ to $50 \%$ of the root cross-section with vascular discoloration; and $3=$ more than $50 \%$ of the root cross-section with vascular discoloration. At least 3 roots were assayed for each cultivar. Reaction classes were based on cluster analysis of cultivar means for the severity of root discoloration symptoms. $0 \leq$ resistant $(\mathrm{R}) \leq$ $0.7 ; 0.7<$ moderately resistant $(\mathrm{MR}) \leq 1.2 ; 1.2$ $<$ moderately susceptible (MS) < 2.0; and $2.0 \leq$ susceptible (S). 
ratings of 1,2 , and 3 , respectively. The correlation coefficients, $r=0.54$ and $r_{p}=$ 0.53 , between root discoloration symptoms and recovery of the pathogen were significant $(P<0.001)$. Root discoloration symptoms also correlated $\left(r=0.33, r_{p}=\right.$ $0.44, P<0.001)$ with the severity, and consequently the incidence, of typical foliar symptoms of Verticillium wilt (severity and incidence of typical foliar symptoms were highly correlated with each other, $r_{p}=$ 0.96 and 0.99 in the first and the second trials, respectively). Although 28 (10\%) of the 279 plants that showed typical foliar symptoms had no root symptoms, 29, 50, and $64 \%$ of the sets with root symptom ratings of 1,2 , and 3 , respectively, originated from plants that were already diagnosed as infected based on typical foliar symptoms of Verticillium wilt. Cultivars that exhibited typical foliar symptoms sooner (i.e., had shorter incubation periods) were more likely to have higher ratings for the severity of root discoloration symptoms, as indicated by a significant $(P$ $<0.001)$ correlation, $r_{p}=-0.33$, between root discoloration symptoms and incubation periods. Similarly, the severity of typical foliar symptoms and the recovery of the pathogen were positively correlated $\left(r=0.45, r_{p}=0.51, P<0.001\right)$. The likelihood of recovering the pathogen was three times higher for plants that exhibited typical foliar symptoms $(P=0.62)$ than for those that did not $(P=0.21)$. The correlation coefficients between general foliar symptoms and either root discoloration symptoms or recovery of the pathogen were not significant except in the second trial, in which a correlation was obtained with root discoloration symptoms $(r=$ $0.24, P<0.01)$.

\section{DISCUSSION}

Six sources of resistance to Verticillium wilt of horseradish, 635A, 1236A, 769A, $125 \mathrm{~A}, 761 \mathrm{~A}$, and 28A, were identified among 113 cultivars from the University of

Table 1. Means of incubation periods, severity and incidence of typical foliar symptoms, and percent recovery of the pathogen from 113 horseradish cultivars in four classes of root discoloration reaction to Verticillium dahliae

\begin{tabular}{|c|c|c|c|c|}
\hline \multirow[b]{2}{*}{ Root reaction classes ${ }^{w}$} & \multicolumn{3}{|c|}{ Typical foliar symptoms } & \multirow[b]{2}{*}{ Pathogen recovery $(\%)$} \\
\hline & ${\text { Incubation periods }(\text { days })^{x}}^{x}$ & Severity $^{y}$ & Incidence $(\%)$ & \\
\hline $\mathrm{R}$ & $52 b^{z}$ & $0.5 \mathrm{a}$ & $27 \mathrm{a}$ & $18 \mathrm{a}$ \\
\hline MR & $52 \mathrm{~b}$ & $0.6 \mathrm{a}$ & $29 \mathrm{a}$ & $31 \mathrm{ab}$ \\
\hline MS & $47 \mathrm{ab}$ & $0.7 \mathrm{a}$ & $40 \mathrm{a}$ & $46 \mathrm{bc}$ \\
\hline S & $41 \mathrm{a}$ & $1.3 \mathrm{~b}$ & $61 \mathrm{~b}$ & $58 \mathrm{c}$ \\
\hline
\end{tabular}

${ }^{\mathrm{w}}$ The classes of root reaction, R, MR, MS, and $\mathrm{S},=$ resistant, moderately resistant, moderately susceptible, and susceptible, respectively, and were based on cluster analysis of cultivar means for the severity of root discoloration symptoms rated on a 0 to 3 scale as follows: $0=$ no symptoms; $1=$ trace to less than $10 \%$ of the root cross-section with vascular discoloration; $2=10$ to $50 \%$ of the root cross-section with vascular discoloration; and $3=$ more than $50 \%$ of the root cross-section with vascular discoloration. $0 \leq \mathrm{R} \leq 0.7 ; 0.7<\mathrm{MR} \leq 1.2 ; 1.2<\mathrm{MS}<2.0$; and $2.0 \leq \mathrm{S}$; with 17,43 , 48, and 5 cultivars, respectively.

$\mathrm{x}$ Number of days from inoculation to the first appearance of foliar symptoms typical of Verticillium wilt.

${ }^{y}$ On a 0 to 5 rating scale, as follows: $0=$ no symptoms or any ambiguous symptoms, including the stunting of the plant, that could not be confidently related to $V$. dahliae; 1 = incipient chlorosis typical of Verticillium wilt but limited to one leaf; $2=2$ to less than $25 \%$ of the leaves with chlorosis and necrosis typical of Verticillium wilt; $3=25$ to less than $50 \%$ of the leaves with chlorosis and necrosis typical of Verticillium wilt; $4=50$ to less than $75 \%$ of the leaves with chlorosis and necrosis typical of Verticillium wilt; and $5=$ more than $75 \%$ of the leaves with chlorosis and necrosis typical of Verticillium wilt, or the plant is dead as a result of foliar symptoms previously identified as typical of Verticillium wilt.

${ }^{\mathrm{z}}$ For each column, means followed by the same letter are not significantly different $(P>0.05)$ according to Fisher's least significant difference test.

Table 2. Root discoloration ratings, percentages of pathogen recovery, and classes of root reaction of 22 horseradish cultivars 2 months after root-dip inoculation with Verticillium dahliae (100 microsclerotia/ml water) during two greenhouse trials (1 and 2)

\begin{tabular}{|c|c|c|c|c|c|c|c|c|}
\hline \multirow[b]{2}{*}{ Cultivars } & \multicolumn{2}{|c|}{ Number of roots } & \multicolumn{2}{|c|}{ Root discoloration rating $^{y}$} & \multicolumn{2}{|c|}{ Pathogen recovery $(\%)$} & \multicolumn{2}{|c|}{ Root reaction classes $^{\mathrm{z}}$} \\
\hline & 1 & 2 & 1 & 2 & 1 & 2 & 1 & 2 \\
\hline $635 \mathrm{~A}$ & 8 & 11 & 0.2 & 0.5 & 25 & 0 & $\mathrm{R}$ & $\mathrm{R}$ \\
\hline $1236 \mathrm{~A}$ & 5 & 11 & 0.6 & 0.3 & 40 & 0 & $\mathrm{R}$ & $\mathrm{R}$ \\
\hline $769 \mathrm{~A}$ & 7 & 12 & 0.6 & 0.6 & 29 & 8 & $\mathrm{R}$ & $\mathrm{R}$ \\
\hline $125 \mathrm{~A}$ & 3 & 5 & 0.7 & 0.4 & 67 & 33 & $\mathrm{R}$ & $\mathrm{R}$ \\
\hline $761 \mathrm{~A}$ & 7 & 4 & 0.7 & 0.5 & 14 & 25 & $\mathrm{R}$ & $\mathrm{R}$ \\
\hline $28 \mathrm{~A}$ & 6 & 3 & 0.7 & 0.7 & 0 & 0 & $\mathrm{R}$ & $\mathrm{R}$ \\
\hline $812 \mathrm{~A}$ & 6 & 7 & 0.5 & 0.9 & 17 & 25 & $\mathrm{R}$ & MR \\
\hline $772 \mathrm{~A}$ & 7 & 11 & 0.5 & 0.9 & 17 & 27 & $\mathrm{R}$ & MR \\
\hline $829 A$ & 8 & 8 & 0.6 & 0.9 & 25 & 13 & $\mathrm{R}$ & MR \\
\hline $1726 \mathrm{~A}$ & 8 & 10 & 0.6 & 0.9 & 25 & 20 & $\mathrm{R}$ & MR \\
\hline $1728 \mathrm{~A}$ & 7 & 5 & 0.6 & 1.0 & 14 & 0 & $\mathrm{R}$ & MR \\
\hline 839A & 7 & 7 & 0.7 & 0.9 & 0 & 13 & $\mathrm{R}$ & MR \\
\hline $810 \mathrm{~A}$ & 7 & 8 & 0.7 & 1.0 & 29 & 25 & $\mathrm{R}$ & MR \\
\hline $196 \mathrm{~A}$ & 4 & 8 & 0.7 & 1.0 & 0 & 13 & $\mathrm{R}$ & MR \\
\hline $872 \mathrm{~A}$ & 6 & 9 & 0.3 & 1.1 & 0 & 22 & $\mathrm{R}$ & MR \\
\hline $109 \mathrm{~A}$ & 5 & 3 & 0.8 & 0.3 & 40 & 33 & MR & $\mathrm{R}$ \\
\hline 1091A & 8 & 9 & 0.9 & 0.8 & 63 & 11 & MR & MR \\
\hline $785 \mathrm{~A}$ & 4 & 4 & 0.2 & 1.3 & 0 & 25 & $\mathrm{R}$ & MS \\
\hline $797 \mathrm{~A}$ & 3 & 10 & 0.3 & 1.3 & 0 & 50 & $\mathrm{R}$ & MS \\
\hline $1005 \mathrm{~A}$ & 8 & 10 & 1.4 & 1.4 & 50 & 58 & MS & MS \\
\hline $647 \mathrm{~A}$ & $\ldots$ & 10 & $\ldots$ & 1.3 & $\ldots$ & 40 & $\ldots$ & MS \\
\hline $1405 \mathrm{~A}$ & 6 & 7 & 2.5 & 1.9 & 67 & 57 & $\mathrm{~S}$ & MS \\
\hline
\end{tabular}

y On a 0 to 3 scale as follows: $0=$ no symptoms; $1=$ trace to less than $10 \%$ of the root cross-section with vascular discoloration; $2=10$ to $50 \%$ of the root cross-section with vascular discoloration; and $3=$ more than $50 \%$ of the root cross-section with vascular discoloration. Each figure represents the mean for the corresponding number of roots examined.

${ }^{\mathrm{z}}$ Based on cultivar means for the severity of root discoloration symptoms, with $0 \leq$ resistant $(\mathrm{R}) \leq 0.7 ; 0.7<$ moderately resistant $(\mathrm{MR}) \leq 1.2 ; 1.2<$ moderately susceptible (MS) $<2.0$; and $2.0 \leq$ susceptible (S). 
Illinois horseradish germ plasm collection at Urbana. An examination of the pedigree of each of these 6 cultivars reveals that 2 of them, 761A (PI 305626) and 769A (PI 305634), were introduced into the United States from Poland (15). It is not surprising that the primary source of resistance to $V$. dahliae comes from that region of temperate eastern Europe, where the horseradish plant is presumed to be indigenous (4), and where the pathogen and its host may have co-existed for a long period of time. The 4 other sources of resistance originate from cultivars developed in the United States. Cultivar 635A was derived from a seedling of the "Swiss" type cultivar, 868A. Cultivar $28 \mathrm{~A}$ is a hybrid obtained from a cross between IC-1 (Illinois common 1) and Sass (an accession from Canada). Cultivar 125A is an offspring of $\mathrm{X}-1$, a hybrid that was developed at the Wisconsin Agricultural Experimentation Station from a cross involving a "common" and a "bohemian" type of horseradish (21). Cultivar 1236A resulted from a series of polycrosses that involved 208A, 797A, and 849A (PI 317042) as female parents.

Besides the 6 cultivars classified as resistant in both trials, 11 cultivars were classified as either resistant or moderately resistant in the two trials. This group includes some interesting materials, such as 772A (PI 306121), a cultivar that was already presumed to have a good level of resistance based on observations from growers' fields. Cultivar 1005A, grown widely in Illinois, was classified as moderately susceptible in both trials, in contrast to a previous study suggesting that this cultivar is comparatively resistant (J. A. Juvik, personal communication).

The frequency distribution of the 113 cultivars for the severity of root discoloration symptoms shows that the mean for the cultivars in this germ plasm collection is in the most diseased end of the moderately resistant class. The cultivars exhibited a large amount of variation for the severity of root discoloration symptoms, with means ranging from 0.2 to 2.6 on a 0 to 3 scale. The existence of such variability within the University of Illinois horseradish germ plasm collection shows that there is a great potential for the breeding of improved horseradish cultivars combining both resistance to $V$. dahliae and other desirable characters $(8,20,22)$. First, the resistant reactions identified in these greenhouse trials must be confirmed under field conditions. Then, resistant cultivars can either be increased and released to growers, or improved further through breeding. In the latter alternative, the application of combinatory breeding methods (6) to horseradish should face no major problem, because many cultivars from this germ plasm collection, including the resistant ones, can produce viable seed (1). Although we used set roots to evaluate horseradish cultivars for resistance to $V$. dahliae, the screening of seed-grown plants represents another promising way of identifying sources of resistance. The root-dip inoculation technique (2) should be applicable here. Therefore, this operation should be carried out routinely, as new combinations of genotypes arise from the natural cross-pollination of cultivars that takes place every year in this horseradish germ plasm collection.

In our study, resistance to Verticillium wilt of horseradish was based on the severity of the root discoloration symptom, a phenotype that was previously shown to be associated with $V$. dahliae infection (5). Our results support the choice of the root discoloration symptom as a measure of resistance to $V$. dahliae. Not only did this symptom correlate with the recovery of the pathogen, but also the classes of root reaction based on the root discoloration symptom were consistent with respect to the other characters observed. The problem with root discoloration symptoms, however, is that they can be evaluated only after harvest. This may become a serious limitation, especially with some breeding procedures such as the backcross method, where the assessment of resistance early in the course of the plant development is desirable (6). On horseradish, foliar symptoms have been used as a preliminary indicator of infection by $V$. dahliae $(3,12)$. However, Chang and Eastburn (3) found no correlation between foliar and root symptoms. Eastburn and Chang (5) concluded that foliar symptoms were unreliable, on the grounds that root symptoms could be observed from plants that showed no foliar symptoms. The latter authors, nonetheless, admitted that when typical foliar symptoms were observed, root discoloration symptoms were almost always present. The solution, therefore, lies in our ability to identify typical foliar symptoms of Verticillium wilt of horseradish.

We have shown that when foliar symptoms were recorded indiscriminately (3), no correlation usually was obtained between foliar symptoms and either root symptoms or recovery of the pathogen. In contrast, both correlations were significant and the recovery of the pathogen was higher when typical foliar symptoms were considered. Interestingly, the resistant and susceptible classes of cultivars differed significantly for the incubation periods and for the severity and incidence of typical foliar symptoms. Clearly, these results suggest that typical foliar symptoms of Verticillium wilt can be useful for identifying undesirable horseradish cultivars. Specifically, cultivars with shorter incubation periods and high ratings of severity and incidence of typical foliar symptoms could justifiably be considered as susceptible, and therefore screened out of a breeding program at earlier stages. Evaluation of root symptoms would then be necessary to categorize the reactions of the remaining cultivars. From a practical standpoint, the high correlation between severity and incidence of typical foliar symptoms shows that the task of evaluating these symptoms could be greatly simplified with a disease incidence rating instead of a disease severity rating (17).

\section{ACKNOWLEDGMENTS}

We thank G. Z. Gertner, professor of Biometrics, Department of Natural Resources and Environmental Sciences, for statistical assistance; and J. K. Pataky and W. L. Pedersen, Department of Crop Sciences, and the two anonymous reviewers for their useful comments during the preparation of the manuscript.

\section{LITERATURE CITED}

1. Atibalentja, N. 1995. Evaluation of the University of Illinois horseradish germplasm collection for resistance to Verticillium dahliae Klebahn. M.S. thesis, University of Illinois, Urbana.

2. Atibalentja, N., and Eastburn, D. M. 1997. Evaluation of inoculation methods for screening horseradish cultivars for resistance to Verticillium dahliae. Plant Dis. 81:356-362.

3. Chang, R. J., and Eastburn, D. M. 1994. Host range of Verticillium dahliae from horseradish and pathogenicity of strains. Plant Dis. 78:503-506.

4. Couter, J. W., and Rhodes, A. M. 1969. Historical notes on horseradish. Econ. Bot. 23:156-164.

5. Eastburn, D. M., and Chang, R. J. 1994 Verticillium dahliae: A causal agent of root discoloration of horseradish in Illinois. Plant Dis. 78:496-498.

6. Fehr, W. R. 1993. Principles of Cultivar Development, Vol. 1: Theory and Technique. Iowa State University, Ames.

7. Gerber, J. M., Doll, C. C., Simons, R. K., and Fillingim, K. E. 1983. Internal discoloration of horseradish-development of symptoms. Univ. Ill. Veg. Res. Rep. Hortic. Ser. 47:3437.

8. Innes, N. L. 1992. Gene banks and their contribution to the breeding of disease resistant cultivars. Pages 23-31 in: Breeding for Disease Resistance. R. Johnson and G. J. Jellis, eds. Kluwer Academic Publishers, London.

9. Kadow, K. J., and Anderson, H. W. 1940. A study of horseradish diseases and their control. Univ. Ill. Agric. Exp. Stn. Bull. 469.

10. Klecka, W. R. 1980. Discriminant Analysis. Sage University Paper series on Quantitative Applications in the Social Sciences, 07-019. Sage Publications, Newbury Park, CA.

11. Milligan, G. W., and Cooper, M. C. 1985. An examination of procedures for determining the number of clusters in a data set. Psychometrika 50:159-179.

12. Mueller, J. P., Percich, J. A., and Mitchell, J. E. 1982. Root deterioration associated with Verticillium wilt of horseradish. Plant Dis. 66:410-414.

13. Percich, J. A., and Johnson, D. R. 1990. A root rot complex of horseradish. Plant Dis. 74:391-393.

14. Rhodes, A. M. 1977. Horseradish-Problems and Research in Illinois. Pages 137-147 in: Crop Resources. Academic Press, Inc., New York.

15. Rhodes, A. M. 1982. Horseradish germplasm collection. Univ. Ill. Agric. Exp. Stn. Dep. Hortic.

16. Rhodes, A. M., Courter, J. W., Shurtleff, M. C., and Vandemark, J. S. 1965. Improving horseradish through breeding. Ill. Res. Univ. Ill. Agric. Exp. Stn. 7:17.

17. Seem, R. C. 1984. Disease incidence and severity relationships. Annu. Rev. Phytopa- 
thol. 22:133-150.

18. Steel, R. G. D., and Torrie, J. H. 1980. Principles and Procedures of Statistics: a Biometrical Approach. 2nd ed. McGraw-Hill Publish. Co., New York.

19. U.S. Dep. Agric. 1972. Commercial growing of horseradish. Leaflet No. 547. U.S. Govern- ment Printing Office, Washington, DC.

20. Walker, J. C. 1975. Breeding for resistance to soil-borne pathogens. Pages 164-165 in: Biology and control of soil-borne plant pathogens. G. W. Bruehl, ed. Third International Symposium, 1973. American Phytopathological Society, St. Paul, MN
21. Weber, W. W. 1949. Seed production in horseradish. J. Hered. 40:223-227.

22. Williams, P. H. 1989. Screening for resistance to diseases. Pages 335-352 in: The Use of Plant Genetic Resources. A. H. D. Brown, O. H. Frankel, D. R. Marshall, and J. T. Williams, eds. Cambridge University Press, New York. 